Bulletin of Pharmaceutical_Sciences
Assiut University

\title{
STEVIA IMPROVES THE ANTIHYPERGLYCEMIC EFFECT OF METFORMIN IN STREPTOZOTOCIN-INDUCED DIABETIC RATS: A NOVEL STRATEGY IN TYPE 2 DIABETES MELLITUS
}

\author{
Raafat A. Abdel-Aal ${ }^{1}$, Mahran S. Abdel-Rahman ${ }^{1}$ and Laila A. Ali ${ }^{2 *}$ \\ ${ }^{1}$ Department of Pharmacology, Faculty of Medicine, Assiut University, Egypt \\ ${ }^{2}$ Department of Pharmacology, Faculty of Pharmacy, Assiut University, Egypt
}

\begin{abstract}
Diabetes mellitus is a major health problem that threatens the whole world. According to WHO reports, the prevalence of diabetic patients in egyptis expected to increase from 2,623,000 in 2000 to be 6,726,000 in 2030. Metformin is the first line drug for type 2 diabetes mellitus, which can be used alone or in combination with other drugs. However, the concomitant use of metformin with stevia needs more investigation to clarify the role of this combination as a new strategy in type 2 diabetes mellitus.

Type 2 diabetes mellitus was induced in rats by i.p. injection of STZ and NA. Animals were divided into five groups, each contains 8 rats. Group I: negative control, group II: diabetic control received saline, group III: diabetic rats received $400 \mathrm{mg} / \mathrm{kg} /$ day stevia aqueous extract, group IV: diabetic rats received metformin $250 \mathrm{mg} / \mathrm{kg} /$ day, group $V$ : diabetic rats received stevia $400 \mathrm{mg} / \mathrm{kg} /$ day + metformin $250 \mathrm{mg} / \mathrm{kg} /$ day. After 3 weeks blood samples were collected, animals were sacrificed and tissue samples were collected. Biochemical parameters including $F B G$, serum insulin, serum DPP-4, TC, TG, LDL, HDL, GSH and MDA were measured by colorimetric and ELISA methods.

Both stevia and metformin significantly reduced FBG level. While serum insulin significantly increased. Serum DPP-4 was significantly reduced in all treated groups, concerning lipid profile, stevia and metformin significantly lowered TC, TG, LDLand increased HDL. Both stevia and metformin significantly decreased MDA and increased GSH compared to diabetic rats. In addition, stevia significantly improved the antidiabetic effects of metformin.

Stevia has an antihyperglycemic effect and could increase the antidiabetic activity of metformin. DPP-4 attenuation, antioxidant and insulin-sensitizing effects may be involved in the antidiabetic action of stevia. Regarding lipid profile stevia showed hypolipidemic effect.
\end{abstract}

\section{INTRODUCTION}

Diabetic patients are increasing in number all over the world due to population growth, aging, urbanization, and increasing prevalence of obesity and physical inactivity. Therefore, the number of people with diabetes in the world is expected to approximately double between 2000 and $2030^{1}$. According to WHO reports, the prevalence of diabetic patients in egypt is expected to increase from 2,623,000 in 2000 to be $6,726,000$ in $2030^{2}$.

Metformine is the most commonly prescribed drug for type 2 diabetes mellitus ${ }^{3}$. In recent years, in addition to glucose lowering, several studies have presented evidence suggesting some potential role of metformin, such as antitumor effect, antiaging effect, cardiovascular protective effect, neuroprotective effect or an optional treatment for polycystic ovary syndrome ${ }^{4}$.

Stevia rebaudiana Bertoni is a perennial herb belonging to the Asteraceae family. It is a natural sweetener plant known as "Sweet Weed", "Sweet Leaf", "Sweet Herbs" and "Honey Leaf", which is estimated to be 300 times more sweeting than sugar $\mathrm{can}^{5}$. The leaves of Stevia contain a natural complex 
mixture of eight sweet diterpene glycosides, including isosteviol, stevioside, rebaudiosides (A, B, C, D, E, F), steviolbioside and dulcoside $A^{6 \& 7}$. Stevia leaf extracts have been used traditionally by folks in the treatment of diabetes mellitus ${ }^{8}$. Their ingestion causes a slight decrease in plasma glucose levels and significantly increase glucose tolerance in normal adult humans ${ }^{9}$. However, the beneficial effects from using combination of stevia and metformin so far not well documented. Therefore, this study was planned to clarify the role of stevia-metformin combination in type 2 diabetes in diabetic rats.

\section{MATERIALS AND METHODS}

\section{Chemicals}

Streptozotocin (STZ), nicotinamide (NA) obtained from cornal lab company, metformin gifted by said factory, stevia aqueous extract supplied by pharmacognosy department faculty of pharmacy assiut university.

\section{Animals}

Male albino rats were used in this study. They weighed 200 to $250 \mathrm{~g}$ and were maintained in 12- hrs light/dark cycle. The animals had free access to food and water was given through drinking bottles.

\section{Induction of diabetes}

Diabetes was induced in the overnightfasted rats by a single intraperitoneal injection of STZ $(60 \mathrm{mg} / \mathrm{kg})$, fifteen minutes after the I.P. administration of nicotinamide (120 $\mathrm{mg} / \mathrm{kg}$ ). Their blood glucose levels were measured 3 days after the STZ injection. Only rats with fasting blood glucose levels greater than $220 \mathrm{mg} / \mathrm{dL}$ were considered to be diabetic and were used in the experiment ${ }^{10}$.

\section{Preparation of plant extract}

$5 \mathrm{~kg}$ of the air-dried powdered leaves of Stevia rebaudiana Bertoni were extracted by maceration in $70 \% \mathrm{EtOH}(10 \mathrm{~L} \times 3)$. The alcoholic extract was concentrated and the solvent free residue $(835 \mathrm{~g})$. Part of the alcoholic extract $(425 \mathrm{~g})$ was mixed with 500 $\mathrm{mL}$ of distilled $\mathrm{H}_{2} \mathrm{O}$, and subjected to successive solvent fractionation with dichloromethane till complete exhaustion. The Dichloromethane fraction was concentrated and the solvent free residue was $(87 \mathrm{~g})$. The aqueous fraction was concentrated and the solvent free residue was $(336 \mathrm{~g})^{11}$.

\section{Experimental design}

Animals were divided into 5 groups each group contained 8 rats as follow:

1- Negative control group included nondiabetic rats.

2- Diabetic control group included 3-diabetic rats received normal saline

3- Diabetic rats received stevia extract $400 \mathrm{mg} / \mathrm{kg}$.

4- Diabetic rats received metformin $250 \mathrm{mg}$ $/ \mathrm{kg}$.

5- Diabetic rats received stevia extract $400 \mathrm{mg} / \mathrm{kg}+$ metformin $250 \mathrm{mg} / \mathrm{kg}$.

All drugs administered orally by stomach tube.

After 21 days blood samples were collected from retro orbital sinus ${ }^{12}$, animals were sacrificed under light ether anesthesia and parts of liver and kidney collected for biochemical measurement.

\section{Preparation of tissue homogenate}

Liver and kidney were excised immediately after sacrificed, cleaned in saline, homogenized in 10\% (w/v) ice cold $100 \mathrm{mM}$ phosphate buffer $(\mathrm{pH}$ 7.4) and centrifuged at $10,000 \mathrm{rpm}$ for $15 \mathrm{~min}$ at $4^{\circ} \mathrm{C}$, and then the supernatant was obtained and used for oxidative stress biomarkers studies ${ }^{13}$.

\section{Measurements}

The serum glucose was estimated by enzymatic colorimetric method ${ }^{14}$. Both serum insulin and DPP-4 were estimated by using (ELISA) technique.

Serum total cholesterol is estimated by enzymatic colorimetric method ${ }^{15}$. Serum high density lipoprotein cholesterol was estimated by enzymatic colorimetric method precipitating reagent ${ }^{16}$. The serum low density lipoprotein cholesterol was estimated by enzymatic colorimetric method precipitating reagent ${ }^{17}$. The serum triglycerides was estimated by enzymatic colorimetric method ${ }^{18}$. The level of reduced glutathione in liver and kidney tissues was estimated by colorimetric method ${ }^{19}$. The level of malodialdehyde in liver and kidney tissues was estimated by colorimetric method ${ }^{20}$. 
In order to detect insulin resistance we evaluated HOMA-IR (homeostatic model assessment of insulin resistance) using the following formula: (fasting plasma insulin in $\mathrm{mU} / \mathrm{l}$ x FPG in mmol/l) / $22.5^{21}$. For evaluation of insulin sensitivity used the formula, IS $=1 /$ HOMA-IR ${ }^{22}$.

\section{RESULTS AND DISCUSSION}

\section{Results}

Effect of stevia, metformin, and their combination on fasting blood glucose level (FBG)

Treatment of diabetic rats with stevia aqueous extract or metformin showed a significant decrease in FBG $(\mathrm{p}<0.001)$ compared to positive control rats. Combined administration of stevia aqueous extract plus metformin produced a significant decrease in FBG $(p<0.001)$ compared to the positive control, stevia and metformin treated rats (Fig. $1)$.

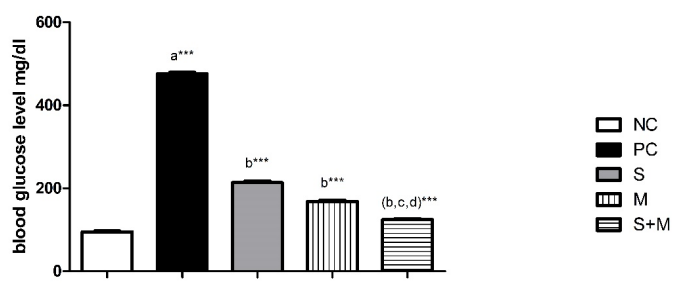

Fig. 1: Effect of $400 \mathrm{mg} / \mathrm{kg}$ stevia aqueous extract, metformin $250 \mathrm{mg} / \mathrm{kg}$ and their combination on FBG mg / dl.

NC: negative control, PC: positive control, S: stevia and $\mathbf{M}$ : metformin.

a: significantly different from the mean value of the negative control rats, $\mathbf{b}$ : significantly different from the mean value of the positive control rats, c: significantly different from the mean value of the stevia-treated rats, d: significantly different from the mean value of the metformin-treated rats.

$\mathbf{P}(*<0.05, * *<0.01, * * *<0.001) . \mathrm{N}=8$. Values are mean \pm standard error of the mean (SEM)

Effect of stevia, metformin, and their combination onserum insulin level

Both stevia aqueous extract and metformin produced a significant increase in serum insulin level $(\mathrm{p}<0.001)$ compared to positive control rats. Additionally, co-administration stevia aqueous extract plus metformin produced a significant increase in serum insulin level $(\mathrm{p}<$ 0.001) compared to the positive control, stevia and metformin-treated rats (Fig. 2).

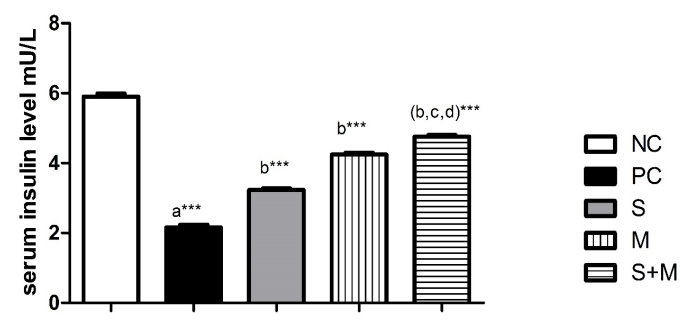

Fig. 2: Effect of $400 \mathrm{mg} / \mathrm{kg} /$ day stevia aqueous extract, metformin $250 \mathrm{mg} / \mathrm{kg}$ and their combination on serum insulin level mU/L.

NC: negative control, PC: positive control, $\mathbf{S}$ : stevia and $\mathbf{M}$ : metformin, a: significantly different from the mean value of the negative control rats, b: significantly different from the mean value of the positive control rats, c: significantly different from the mean value of the stevia treated rats, $\mathbf{d}$ : significantly different from the mean value of the metformin treated rats.

$\mathbf{P}(*<0.05, * *<0.01, * * *<0.001) . \mathrm{N}=8$. Values are mean \pm SEM.

Effect of stevia, metformin, and their combination on HOMA-IR and insulin sensitivity

Stevia aqueous extract or metformin produced a significant decrease in HOMA-IR $(\mathrm{p}<0.001)$ compared to the positive control rats. The same finding was noticed following daily oral treatment of animals with combinations of stevia aqueous extract plus metformin produced a significant decrease in HOMA-IR $(\mathrm{p}<0.001)$ compared to positive control, a significant decrease in HOMA-IR $(\mathrm{P}<0.05)$ compared to stevia, and a significant decrease in HOMA-IR $(\mathrm{P}<0.01)$ compared to metformin-treated rats.

Stevia aqueous extract or metformin produced a significant increase in insulin sensitivity $(p<0.001)$ compared to positive control rats. Similarly, stevia aqueous extract combined with metformin showed a significant increase in insulin sensitivity $(\mathrm{p}<0.001)$ compared to positive control, stevia and metformin-treated rats (Table 1). 
Table 1: Effect of stevia, metformin and their combination on HOMA-IR, and Insulin sensitivity (IS).

\begin{tabular}{|l|l|l|l|l|l||}
\hline & $\begin{array}{l}\text { Negative } \\
\text { control }\end{array}$ & $\begin{array}{l}\text { Diabetic } \\
\text { control }\end{array}$ & Stevia & Metformin & Stevia + Metformin \\
\hline HOMA-IR & $1.37 \pm 0.04$ & $2.54 \pm 0.09^{\mathrm{a}^{* * * *}}$ & $1.72 \pm 0.03^{\mathrm{b}^{* * * *}}$ & $1.78 \pm 0.05^{\mathrm{b}^{* * * *}}$ & $1.46 \pm 0.04^{\mathrm{b}^{* * * *}, \mathrm{c}^{* *}, \mathrm{~d}^{* * *}}$ \\
\hline IS & $0.73 \pm 0.02$ & $0.40 \pm 0.01^{\mathrm{a}^{* * * *}}$ & $0.58 \pm 0.01^{\mathrm{b}^{* * * *}}$ & $0.57 \pm 0.01^{\mathrm{b}^{* * * *}}$ & $0.69 \pm 0.02^{(\mathrm{b}, \mathrm{c}, \mathrm{d})^{* * * *}}$ \\
\hline
\end{tabular}

Values are mean \pm SEM., $N=8$. a: significantly different from the mean value of the negative control rats. b: significantly different from the mean value of the diabetic control rats c: significantly different from the mean value of the stevia treated rats $\mathbf{d}$ : significantly different from the mean value of the metformin treated rats. $\mathbf{P}(*<0.05, * *<0.01, * * *<0.001)$.

Effect of stevia, metformin and their combination on DPP 4 level

Stevia aqueous extract or metformin produced a significant decrease in DPP 4 level $(\mathrm{p}<0.001)$ compared to positive control rats. It can be seen in the same figure combined administration of stevia aqueous extract orally with metformin produced a significant decrease in DPP 4 level $(\mathrm{p}<0.001)$ compared to positive control, stevia and metformin treated rats (Fig. $3)$.

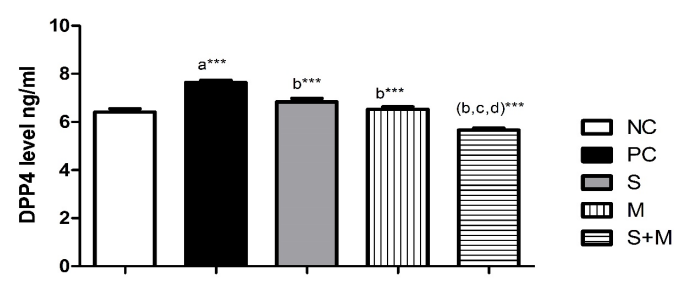

Fig. 3: Effect of $400 \mathrm{mg} / \mathrm{kg}$ stevia aqueous extract, metformin $250 \mathrm{mg} / \mathrm{kg}$ and their combination on DPP 4 level $\mathrm{ng} / \mathrm{ml}$.

NC: negative control, PC: positive control, $\mathbf{S}$ : stevia and $\mathbf{M}$ : metformin.

a: significantly different from the mean value of the negative control rats, $\mathbf{b}$ : significantly different from the mean value of the positive control rats, c: significantly different from the mean value of the stevia treated rats, $\mathbf{d}$ : significantly different from the mean value of the metformin treated rats. $\mathbf{P}(*<0.05$, $* *<0.01, * * *<0.001) . \mathrm{N}=8$.

Values are mean \pm SEM.

\section{Effect of stevia, metformin and their} combination on lipid profile

Both stevia aqueous extract and metformin produced a significant decrease in total cholesterol level $(\mathrm{p}<0.001)$ compared to positive control rats. The same table showed that combined administration of stevia aqueous extract with metformin produced a significant decrease in total cholesterol level $(\mathrm{p}<0.001)$ compared to positive control, stevia and metformin treated rats.
Similarly, stevia aqueous extract or metformin produced a significant decrease in triglycerides level $(\mathrm{p}<0.001)$ compared to positive control rats. Also, combined daily administration of stevia aqueous extract with metformin produced a significant decrease in triglycerides level $(\mathrm{p}<0.001)$ compared to positive control, stevia and metformin treated rats.

Stevia aqueous extract or metformin produced a significant increase in HDL level $(\mathrm{p}<0.001)$ compared to positive control rats. The same table showed that combined administration of stevia aqueous extract with metformin produced a significant increase in HDL level $(\mathrm{p}<0.001)$ compared to positive control, stevia and a significant increase $(\mathrm{p}<$ 0.01) compared to metformin treated rats.

As expected both stevia aqueous extract and metformin produced a significant decrease in LDL level $(p<0.001)$ compared to positive control rats. The same table showed that combined administration stevia aqueous extract with metformin produced a significant decrease in LDL level $(p<0.001)$ compared to positive control, stevia and metformin treated rats (Table 2).

\section{Antioxidant effect of stevia, metformin and their combination}

1- Effect of stevia, metformin and their combination on reduced glutathione (GSH) level in liver and kidney tissues

Stevia aqueous extract or metformin produced a significant increase in GSH in liver and kidney tissues $(\mathrm{p}<0.001)$ compared to positive control rats. The same finding when stevia aqueous extract combined with metformin produced a significant increase in GSH in liver and kidney tissues $(\mathrm{p}<0.001)$ compared to positive control, stevia and metformin treated rats (Table 3 ). 
Table 2: Effect of stevia, metformin and their combination onserum lipid profile.

\begin{tabular}{|c|c|c|c|c|c||}
\hline & $\begin{array}{c}\text { Negative } \\
\text { control }\end{array}$ & Diabetic control & Stevia & Metformin & Stevia + Metformin \\
\hline $\begin{array}{c}\text { TC } \\
(\mathrm{mg} / \mathrm{dl})\end{array}$ & $105.7 \pm 1.53$ & $199.9 \pm 2.97^{\mathrm{a}^{* * * *}}$ & $155.7 \pm 1.45^{\mathrm{b}^{* * * *}}$ & $139.3 \pm 1.56^{\mathrm{b}^{* * *}}$ & $125.9 \pm 1.14^{(\mathrm{b}, \mathrm{c}, \mathrm{d})^{* * * *}}$ \\
\hline $\begin{array}{c}\mathrm{TGs} \\
(\mathrm{mg} / \mathrm{dl})\end{array}$ & $98.53 \pm 3.41$ & $252.6 \pm 2.35^{\mathrm{a}^{* * * *}}$ & $158.6 \pm 1.99^{\mathrm{b}^{* * * *}}$ & $157.5 \pm 2.00^{\mathrm{b}^{* * * *}}$ & $138.0 \pm 1.35^{(\mathrm{b}, \mathrm{c}, \mathrm{d})^{* * * *}}$ \\
\hline $\begin{array}{c}\mathrm{HDL} \\
(\mathrm{mg} / \mathrm{dl})\end{array}$ & $57.21 \pm 1.08$ & $24.52 \pm 1.13^{\mathrm{a}^{* * *}}$ & $36.61 \pm 0.93^{\mathrm{b}^{* * * *}}$ & $39.64 \pm 1.55^{\mathrm{b}^{* * * *}}$ & $45.87 \pm 0.83^{(\mathrm{b}, \mathrm{c})^{* * *}, \mathrm{~d}^{* * *}}$ \\
\hline $\begin{array}{c}\mathrm{LDL} \\
(\mathrm{mg} / \mathrm{dl})\end{array}$ & $28.75 \pm 1.89$ & $124.8 \pm 3.64^{\mathrm{a}^{* * *}}$ & $87.38 \pm 2.08^{\mathrm{b}^{* * * *}}$ & $68.12 \pm 2.32^{\mathrm{b}^{* * *}}$ & $52.42 \pm 1.53^{(\mathrm{b}, \mathrm{c}, \mathrm{d}) * * *}$ \\
\hline
\end{tabular}

Values are mean \pm SEM., $N=8$. a: significantly different from the mean value of the negative control rats. b: significantly different from the mean value of the diabetic control rats. c: significantly different from the mean value of the stevia treated rats. d: significantly different from the mean value of the metformin treated rats. $\mathbf{P}(*<0.05, * *<0.01, * * *<0.001)$.

Table 3: Effect of stevia, metformin and their combination on GSH and MDA levels in liver and kidney tissues.

\begin{tabular}{|c|c|c|c|c|c|}
\hline & $\begin{array}{c}\text { Negative } \\
\text { control }\end{array}$ & Diabetic control & Stevia & Metformin & Stevia + Metformin \\
\hline $\begin{array}{c}\text { GSH liver } \\
(\mathrm{mg} / \mathrm{g})\end{array}$ & $21.93 \pm 1.03$ & $3.17 \pm 0.46^{\mathrm{a}^{* * *}}$ & $12.33 \pm 0.43^{\mathrm{b}^{* * * *}}$ & $12.32 \pm 0.55^{\mathrm{b}^{* * * *}}$ & $17.20 \pm 0.79^{(\mathrm{b}, \mathrm{c}, \mathrm{d})^{* * *}}$ \\
\hline $\begin{array}{c}\text { GSH } \\
\text { kidney } \\
(\mathrm{mg} / \mathrm{g})\end{array}$ & $21.63 \pm 0.57$ & $6.35 \pm 0.36^{\mathrm{a}^{\mathrm{*} * *}}$ & $17.28 \pm 0.54^{\mathrm{b}^{* * * *}}$ & $15.98 \pm 0.74^{\mathrm{b}^{* * * *}}$ & $21.60 \pm 0.66^{(\mathrm{b}, \mathrm{c}, \mathrm{d})^{* * *}}$ \\
\hline $\begin{array}{c}\text { MDA } \\
\text { liver } \\
\text { (n mol /g) }\end{array}$ & $207.8 \pm 3.49$ & $580.5 \pm 12.24^{\mathrm{a}^{* * *}}$ & $248.8 \pm 4.40^{\mathrm{b} * * *}$ & $242.7 \pm 2.00^{\mathrm{b}^{* * * *}}$ & $207.8 \pm 1.67^{(\mathrm{b}, \mathrm{c},)^{* * * *}, \mathrm{~d}^{* * *}}$ \\
\hline $\begin{array}{c}\text { MDA } \\
\text { kidney } \\
\text { (n mol /g) } \\
\end{array}$ & $209.9 \pm 2.47$ & $455.0 \pm 11.34^{\mathrm{a}^{* * * *}}$ & $240.8 \pm 3.64^{\mathrm{b}^{* * * *}}$ & $264.3 \pm 3.87^{\mathrm{b}^{* * * *}}$ & $226.4 \pm 3.33^{(\mathrm{b}, \mathrm{d})^{* * * *}}$ \\
\hline
\end{tabular}

Values are mean \pm SEM., $\mathrm{N}=8$. a: significantly different from the mean value of the negative control rats. b: significantly different from the mean value of the diabetic control rats. c: significantly different from the mean value of the stevia treated rats. d: significantly different from the mean value of the metformin treated rats. $\mathbf{P}(*<0.05, * *<0.01, * * *<0.001)$.

\section{2- Effect of stevia, metformin and their combination on malodialdehyde (MDA) level in liver and kidney tissues}

Stevia aqueous extract or metformin produced a significant decrease in MDA level in liver and kidney tissues $(\mathrm{p}<0.001)$ compared to positive control rats. Combined administration of stevia aqueous extract with metformin produced a significant decrease in MDA level in both liver tissues $(\mathrm{p}<0.001)$ compared to positive control, stevia and a significant decrease $(\mathrm{p}<0.01)$ compared to metformin treated rats. While, combined administration of stevia aqueous extract with metformin produced a significant decrease in
MDA level in kidney tissue $(\mathrm{p}<0.001)$ compared to positive control and metformin. But, produced no significant change compared to stevia treated rats (Table 3).

\section{Discussion}

Present study showed that aqueous extract of stevia $(400 \mathrm{mg} / \mathrm{kg})$ significantly decreased the blood glucose levels of diabetic rats. These findingis in agreement with those obtained by Misra et al., ${ }^{23}$ who reported that stevia can decrease the blood glucose level of diabetic rats. Similarly, but more recent study reported that the aqueous extract of stevia lowered the blood glucose levels in streptozotocin- induced 
diabetes in rats ${ }^{24}$. However, these studies didn't clarify the exact mechanism of action of stevia in diabetes.On the other side, the mechanism of antihyperglycemic effect of steviosides, the active constituent of stevia, was attributed to the inhibition of phsphoenol pyruvate carboxykinase (PEPCK) gene expression in liver which is responsible for blood glucose level regulation through inhibition of gluconeogenesis $^{25}$. More recently (in 2016), the hypoglycemic activity of the aqueous extract of stevia was explained by PPAR $\gamma$-dependent mechanism and antioxidant properties ${ }^{11}$. The antioxidant property of stevia will be discussed later in this study.

As expected metformin $500 \mathrm{mg} / \mathrm{kg}$ significantly lowered the FBG of diabetic rats. These findings are in agreement with results obtained by Zhou et al., who reported that antihyperglycemic effect of metformin may be mediated by inhibition of AMPK in rat liver and muscles with consequent inhibition of gluconeogenesis in liver and increased glucose uptake in muscles ${ }^{26}$. Whether metformin could activate AMPK in human muscles or not, type 2 diabetic patients received metformin for 10 weeks and then biopsies were taken before treatment began and after 4 and 10 weeks of treatment and AMPK activity was measured in muscle. They found that AMPK 2 activity increased by $52 \%$ after 4 weeks and by $80 \%$ after 10 weeks of treatment with metformin ${ }^{27}$. Very recently, in a differential study Rada et al., (2019) reported that metformin could activate AMPK, inhibit glucose production and increase insulin sensitivity ${ }^{28}$. This study also documented increased insulin sensitivity by metformin but in diabetic rats.

Stevia aqueous extract significantly increased the fasting serum insulin leveland this finding is in the same side with jeppesen $e t$ al., $(2002)^{29}$ they stated that Steviosides could increase insulin secretion by direct action on beta cells. Recently, Piovan et al., (2018) found thatethyl acetate fraction of stevia increased insulin secretion in presence of high glucose concentration. This insulinotropic effect may be attributed to an enhancement of cholinergic and attenuation of adrenergic inhibitory effects on glucose stimulated insulin secretion with a result of an increase in insulin levels in the blood $^{30}$.
In this study, type 2 model of diabetes showed hypoinsulinemia which coincided with $^{31}$ study compared between four different models of type 2 diabetes and concluded that STZ and nicotinamide manifested by hyperglycemia along with hypoinsulinemia. Metformin $250 \mathrm{mg} / \mathrm{kg}$ significantly increased the serum insulin level of hypoinsulinemic diabetic rats this finding in the same side with $^{32 \& 33}$ suggested direct effect of metformin on beta cells or indirect effect ${ }^{34}$ concluded that metformin upregulates incretin receptors on beta cells. Furthermore, this increase in serum insulin may be attributed to the antioxidant properties of metformin ${ }^{35}$. Additionally, this increase could be related to the antiinflammatory activities of metformin ${ }^{36}$ investigated the effect of metformin on experimental insulitis in mice and found that metformin reduced the severity of insulitis further more elevated the serum insulin level. This finding contradicts with ${ }^{37-39}$ as metformin reduces hepatic glucose production, increases peripheral glucose utilization and can reduce insulin resistance without affecting the level of circulating insulin. Our results may document the increase in insulin levels in hypoinsulinemic model of diabetes by metformin.

Concerning insulin sensitivity, in an investigation of the effect of stevia on insulin sensitivity in insulin resistant rats $^{40}$ induced insulin resistance in rats using high fructose diet. Chang et al., found that administration of Steviosides improved insulin sensitivity. Also ${ }^{41}$ reported that stevia could enhance insulin sensitivity and increase serum insulin. The present study in the same side with this as 400 $\mathrm{mg} / \mathrm{kg}$ stevia aqueous extract significantly improved insulin sensitivity while insulin resistance (HOMA-IR) significantly decreased.

Metformin can improve insulin sensitivity by more than one mechanism as it can increase insulin receptor tyrosine kinase activity, enhance glycogen synthesis, and an increase the recruitment and activity of GLUT4 glucose transporters. Concerning adipose tissue, metformin promotes the re-esterification of free fatty acids and inhibits lipolysis, which may indirectly improve insulin sensitivity through reduced lipotoxicity ${ }^{38}$. Recently, in a two years trial the effect of metformin on beta cell function in type 2 diabetic patients of early stage who received initial short-term intensive 
insulin induction is compared with the intermittent insulin therapy (IIT) ${ }^{42}$ showed that metformin is better than IIT since the beta cell functions, insulin sensitivity andglycemic control were maintained in metformin treated group over the 2 years. In this study metformin improved insulin sensitivity and decreased insulin resistance (HOMA-IR).

Dipeptidyl peptidase-4 (DPP-4) plays an important role in degradation of several hormones implicated in glucose hemostasis this opened the window for thinking about the role of DPP-4 in type 2 diabetes pathogenesis, The breakdown of peptides as GLP-1and GIP by DPP-4 catalytic activity ${ }^{43}$, this peptides are important for glucose hemostasis and insulin secretion ${ }^{44}$. Another way is there is a relationship between increased DPP-4 plasma level activity and insulin resistance and impaired insulin signaling ${ }^{45}$. There is a negative correlation between DPP-4 level and active GLP-1 levels in T2DM patients. High DPP-4 levels were associated with increased BMI, cholesterol, and $\mathrm{LDL}^{46}$.

In this study stevia aqueous extract significantly reduced the serum DPP-4 level this finding is in the same way as reported by ${ }^{47}$ who used molecular modeling to study the interaction between compounds extracted from stevia and DPP-4 and found that both stevioside and rebaudioside A inhibited DPP-4 and stevioside produced more optimized inhibition. Steviosides also reported to have the ability to reduce DPP-4 level in diabetic rats ${ }^{48}$.

In an attempt for elucidation of DPP-4 inhibition as a possible mechanism of metformin action, metformin produced a dose dependent inhibition of DPP-4 activity in plasma in type 2 diabetic patients ${ }^{49}$. Similar results obtained in 2006 when metformin decreased the plasma DPP-4 activity in (genetically modified obese) ob/ob mice, increased the circulating level of intact GLP-1 and improved the glucose-lowering and insulinreleasing effects of exogenous GLP-1 administration ${ }^{50}$. Metformin may modulates the incretin axis by PPAR- $\alpha$ dependent mechanism ${ }^{34}$. In accordance with those in the present study daily administration of metformin showed a significant decrease in DPP- 4 level.

The primary genetic, environmental, and metabolic factors responsible for causing insulin resistance and pancreatic $\beta$-cell failure and the precise sequence of events leading to the development of type 2 diabetes are not yet fully understood. Elevated cholesterol and triglycerides lead to dyslipidemia one causatives of insulin resistance ${ }^{51}$. Stevia extract improved the lipid profile of 20 hypercholestremic women, total cholesterol, triglycerides and low density lipoprotein significantly decreased while the high density lipoprotein significantly increased ${ }^{52}$. Recent studies also reported the antihyperlipdemic effect of stevia ${ }^{53}$ investigated the effect of aqueous extract of stevia on hyperglycemia and hyperlipidemia induced by stress in rabbits. Similar results obtained in diabetic rats ${ }^{54 \& 55}$. The present study in the same way with this as daily administration of $400 \mathrm{mg} / \mathrm{kg}$ significantly reduced TC, TGs and LDL while serum HDL significantly increased.

In this study metformin significantly decreased TC, TG, LDL and significantly increased HDLthis finding agreed with previous studies reported the antihyperlipdemic activity of metformin. Metformin improved dyslipidemia in children with metabolic syndrome and suggested as a cardioprotective in risk patients ${ }^{56}$. Recently ${ }^{57}$ concluded that metformin can improve dyslipidemia and reduce cardiac events in type 2 diabetic patients.

Recently, Steviosides showed antioxidant activity and prevented the oxidative damage of DNA in liver and kidney in diabetic rats and significantly elevated the GSH levelcompared to diabeticrats ${ }^{48}$. This study is agree with the previous researches as the daily administration of stevia aqueous extract produced a significant increase in the antioxidant GSH level in liver and kidney tissues furthermore the level of MDA significantly reduced.

In a comparative study the antioxidant activities of metformin, repaglinide and glibenclimide were studied in diabetic rats, metformin significantly increased the antioxidant enzymes catalase (CAT) and superoxide dismutase (SOD). The level of GSH significantly improved while the level of MDA significantly reduced $^{35}$. The renoprotective effect of metformin was investigated in a rat model of type 2 diabetic nephropathy, metformin administered orally for 13 weeks thus produced a significant increment of SOD activity and significantly decreased levels 
MDA, as compared with the model group and attenuated the morphological changes associated with type 2 diabetes in rats. Which suggesting that metformin may has a renoprotection activity ${ }^{58}$. In agreement with this the present study showed that metformin could has a renoprotective and hepatoprotective effect in type 2 diabetes since treatment of diabetic rats produced a significant increase in GSH level in both liver and kidney tissues while the MDA level significantly decreased.

\section{Conclusion}

In conclusion, all the previous parameters shows that stevia has antihyperglycemic effect and significantly improves the effect of metformin in diabetic rats. The antihyperglycemic effect of stevia and its improvement to metformin may be mediated by its antioxidant activity (reduction of MDA and increasing GSH), DPP-4 attenuation, and improvement of lipid profile and improvement of insulin sensitivity.

Abbreviations: DPP-4: dipeptidylpeptidase 4, TC: total cholesterol, TG: triglycerides, LDL: low density lipoprotein, HDL: high density lipoprotein, GSH: reduced glutathione, MDA: malondialdehyde, STZ: streptozotocin, NA: nicotinamide, FBG: fasting blood glucose.

\section{REFERENCES}

1- S. Wild, G. Roglic, A. Green, R. Sicree and H. King, "Global Prevalence of Diabetes. Estimates for the year 2000 and projections for 2030", Diabetes Care, 27 (5), 1047-53 (2004).

2- N. A. Rezk, N. A. Sabbah and M. S. Saad, "Role of microRNA 126 in screening, diagnosis, and prognosis of diabetic patients in Egypt", IUBMB Life, 68 (6), 452-8 (2016).

3- T. Strack, "Metformin: A review", Drugs of Today, 44 (4), 303 (2008).

4- Y-W. Wang, S-J. He, X. Feng, J. Cheng, Y-T. Luo, L. Tian, et al., "Metformin: A review of its potential indications", Drug Des., Deve. Ther., 11, 2421-9 (2017).
5- E. Gupta, S. Purwar, S. Sundaram and G. Rai, "Nutritional and therapeutic values of Stevia rebaudiana: A review", J. Med. Plants Res., 7 (46), 3343-53 (2013).

6- S. K. Goyal, Samsher and R. K. Goyal, "Stevia (Stevia rebaudiana) a biosweetener: A review", IJFSAN, 61 (1), 110 (2010).

7- T. Rajasekaran, A. Ramakrishna, K. Udaya Sankar, P. Giridhar and G. A. Ravishankar, "Analysis of Predominant Steviosides in Stevia rebaudianaBertoni by Liquid Chromatography/Electrospray Ionization-Mass Spectrometry", Food Biotechnol., 22 (2), 179-88 (2008).

8- D. D. Soejarto, A. D. Kinghorn and N. R. Farnsworth, "Potential sweetening agents of plant origin. III. Organoleptic evaluation of Stevia leaf herbarium samples for sweetness", J. Nat. Prod., 45 (5), 590-9 (1982).

9- R. Curi, M. Alvarez, R. Bazotte, L. Botion, J. Godoy and A. Bracht, "Effect of stevia rebuadiana on glucose tolerance in normal adult humans", Braz. J. Med. Biol. Res., (19), 771-774 (1986).

10- S. B. Mishra, A. Verma and M. Vijayakumar, "Preclinical valuation of anti-hyperglycemic and antioxidant action of Nirmali (Strychnos potatorum) seeds in streptozotocin-nicotinamide-induced diabetic Wistar rats: A histopathological investigation", BMG, 5 (4), 157-63 (2013).

11- R. Assaei, P. Mokarram, S. Dastghaib, S. Darbandi, M. Darbandi, F. Zal, et al., "Hypoglycemic effect of aquatic extract of stevia in pancreas of diabetic rats: PPARgamma-dependent regulation or antioxidant potential", Avicenna. J. Med. Biotechnol., 8 (2), 65-74 (2016).

12- S. Parasuraman, K. M. Zhen and R. Raveendran, "Retro-orbital blood sample collection in rats-A video article", PTB Reports, 1 (2), 37-40 (2015).

13- H. Mossa, E. S. Swelam and S. M. M. Mohafrash, "Sub-chronic exposure to fipronil induced oxidative stress, biochemical and histopathological changes in the liver and kidney of male albino rats", Toxicol. Rep., 2, 775-84 (2015). 
14- P. Trinder, "Determination of glucose in blood using glucose oxidase with an alternative oxygen acceptor", Ann. Clin. Biochem., 6 (1), 24-7 (1969).

15- W. Richmond, "Preparation and properties of a cholesterol oxidase from Nocardia sp. and its application to the enzymatic assay of total cholesterol in serum", Clin. Chem., 19 (12), 1350-6 (1973).

16- M. Burstein, H. Scholnick and R. Morfin, "Rapid method for the isolation of lipoproteins from human serum by precipitation with polyanions", JLR, 11 (6), 583-95 (1970).

17- H. Wieland and D. Seidel, "A simple specific method for precipitation of low density lipoproteins", ibid., 24 (7), 904-9 (1983).

18- P. Fossati and L. Prencipe, "Serum triglycerides determined colorimetrically with an enzyme that produces hydrogen peroxide", Clin. Chem., 28 (10), 2077-80 (1982).

19- E. Beutler, O. Duron and B. M. Kelly, "Improved method for the determination of blood glutathione", J. Lab. Clin. Med., 61, 882-8 (1963).

20- H. Ohkawa, N. Ohishi and K. Yagi, "Assay for lipid peroxides in animal tissues by thiobarbituric acid reaction", Anal. Biochem., 95 (2), 351-8 (1979).

21- G. d'Annunzio, M. Vanelli, A. Pistorio and N. Minuto, "Insulin resistance and secrection indexes in healthy Italian children and adolescents: A multicentre study", Acta. Bio. Medica. Atenei. Parmensis., 80 (1), 21-8 (2009).

22- P. A. Sarafidis, A. N. Lasaridis, P. M. Nilsson, M. I. Pikilidou, P. C. Stafilas, A. Kanaki, et al., "Validity and reproducibility of HOMA-IR, 1/HOMAIR, QUICKI and McAuley\&\#39;s indices in patients with hypertension and type II diabetes", JHH, 21, 709-716 (2007).

23- H. Misra, M. Soni, N. Silawat, D. Mehta, B. K. Mehta and D. C. Jain, "Antidiabetic activity of medium-polar extract from the leaves of Stevia rebaudiana Bert. (Bertoni) on alloxan-induced diabetic rats", $\boldsymbol{J}$. Pharm. Bioall. Sci., 3 (2), 242-8 (2011).
24- U. Ahmad and R. S. Ahmad, "Anti diabetic property of aqueous extract of Stevia rebaudiana Bertoni leaves in Streptozotocin-induced diabetes in albino rats", BMC Complement. Altern. Med., 18 (179), 1-11 (2018).

25- T-H. Chen, S-C. Chen, P. Chan, Y-L. Chu, H-Y. Yang and J-T. Cheng, "Mechanism of the hypoglycemic effect of stevioside a glycoside of stevia rebaudiana, Planta. Medica., 108-13 (2005).

26- G. Zhou, R. Myers, Y. Li, Y. Chen, X. Shen, J. Fenyk-Melody, et al., "Role of AMP-activated protein kinase in mechanism of metformin action", J. Clin. Invest., 108 (8), 1167-74 (2001).

27- N. Musi, M. F. Hirshman, J. Nygren, M. Svanfeldt, P. Bavenholm, O. Rooyackers, et al., "Metformin Increases AMPActivated Protein Kinase Activity in Skeletal Muscle of Subjects With Type 2 Diabetes", Diabetes, 51 (7), 2074-81 (2002).

28- P. Rada, A. Mosquera, J. Muntané, F. Ferrandiz, L. Rodriguez-Mañas, F. de Pablo, et al., "Differential effects of metformin glycinate and hydrochloride in glucose production, AMPK phosphorylation and insulin sensitivity in hepatocytes from non-diabetic and diabetic mice", Food Chem. Toxicol., 123, 470-80 (2019).

29- P. B. Jeppesen, S. Gregersen, K. Alstrup and K. Hermansen, "Stevioside induces antihyperglycaemic, insulinotropic and glucagonostatic effects in-vivo: Studies in the diabetic Goto-Kakizaki (GK) rats", Phytomedicine, 9 (1), 9-14 (2002).

30- S. Piovan, A. Pavanello, G. M. L. Peixoto, C. C. I. Matiusso, A. M. P. de Moraes, I. P. Martins, et al., "Stevia Nonsweetener Fraction Displays an Insulinotropic Effect Involving Neurotransmission in Pancreatic Islets", Int. J. Endocrinol., 2018, 3189879 (2018).

31- P-C. Chao, Y. Li, C-H. Chang, J. P. Shieh, J-T. Cheng and K-C. Cheng, "Investigation of insulin resistance in the popularly used four rat models of type-2 diabetes", Biomed. Pharm., 101, 155-61 (2018). 
32- P. Marchetti, S. Del Guerra, L. Marselli, R. Lupi, M. Masini, M. Pollera, et al., "Pancreatic islets from type 2 diabetic patients have functional defects and increased apoptosis that are ameliorated by metformin", J. Clin. Endocrinol. Metab., 89 (11), 5535-41 (2004).

33- G. Patanè, S. Piro, A. M. Rabuazzo, M. Anello, R. Vigneri and F. Purrello, "Metformin restores insulin secretion altered by chronic exposure to free fatty acids or high glucose: A direct metformin effect on pancreatic beta-cells", Diabetes, 49 (5), 735-40 (2000).

34- A. Maida, B. Lamont, X. Cao and D. Drucker, "Metformin regulates the incretin receptor axis via a pathway dependent on peroxisome proliferator-activated receptor- $\alpha$ in mice", Diabetologia., 54 (2), 339-49 (2011).

35- B. Chukwunonso Obi, T. Chinwuba Okoye, V. E. Okpashi, C. Nonye Igwe and E. Olisah Alumanah, "Comparative study of the antioxidant effects of metformin, glibenclamide, and repaglinide in alloxaninduced diabetic rats", J. Diab. Res., 2016, 1-5 (2016).

36- X. Han, Y-L. Tao, Y-P. Deng, J-W. Yu, J. Cai, G-F. Ren, et al., "Metformin ameliorates insulitis in STZ-induced diabetic mice", Peer. J., 5, e3155-68 (2017).

37- S. N. Amin, U. K. Hussein, H. D. Yassa, S. S. Hassan and L. A. Rashed, "Synergistic actions of Vitamin D and metformin on skeletal muscles and insulin resistance of Type 2 Diabetic Rats", $\boldsymbol{J}$. Cell Physiol., 233 (8), 5768-79 (2018).

38- R. Giannarelli, M. Aragona, A. Coppelli and S. Del Prato, "Reducing insulin resistance with metformin: The evidence today", Diab. Metab., 29 (4), 6S28-6S35 (2003).

39- M. Grzybowska, J. Bober and M. Olszewska, "Metformin - mechanisms of action and use for the treatment of type 2 diabetes mellitus", Postepy Higieny I Medycyny Doswiadczalnej, (Online), 65, 277-85 (2011).

40- J-C. Chang, M. Wu, I-M. Liu and J-T. Cheng, "Increase of insulin sensitivity by stevioside in fructose-rich chow-fed rats", HMR, 37 (10), 610-6 (2005).
41- N. Shivanna, M. Naika, F. Khanum and V. K. Kaul, "Antioxidant, anti-diabetic and renal protective properties of Stevia rebaudiana", JDC, 27 (2), 103-13 (2013).

42- R. Retnakaran, H. Choi, C. Ye, C. K. Kramer and B. Zinman, "Two-year trial of intermittent insulin therapy vs metformin for the preservation of $\beta$-cell function after initial short-term intensive insulin induction in early type 2 diabetes", Diab., Obes. Metab., 20 (6), 1399-407 (2018).

43- J. A. Davidson, "Advances in therapy for type 2 diabetes: GLP-1 receptor agonists and DPP-4 inhibitors", Cleveland Clinic Journal of Medicine, 76 (5), S28-S38 (2009).

44- J. J. Holst, C. F. Deacon, T. Vilsbøll, T. Krarup and S. Madsbad, "Glucagon-like peptide-1, glucose homeostasis and diabetes", Trends in Molecular Medicine, 14 (4), 161-8 (2008).

45- D. Lamers, S. Famulla, N. Wronkowitz, S. Hartwig, S. Lehr, D. M. Ouwens, et al., "Dipeptidyl Peptidase 4 Is a Novel Adipokine Potentially Linking Obesity to the Metabolic Syndrome", Diabetes, 60 (7), 1917-25 (2011).

46- R. H. Ahmed, H. Z. Huri, Z. Al-Hamodi, S. D. Salem and S. Muniandy, "Serum Levels of Soluble CD26/Dipeptidyl Peptidase-IV in Type 2 Diabetes Mellitus and Its association with metabolic syndrome and therapy with antidiabetic agents in Malaysian Subjects", PLoS One., 10 (10), 1-12 (2015).

47- H. Ayachi, M. Merad and G. Said, "Study of interaction between dipeptidyl peptidase- 4 and products extracted from the Stevia plant by molecular modeling", IJPS, 87-90 (2013).

48- S. O. Rotimi, O. A. Rotimi, I. B. Adelani, C. Onuzulu, P. Obi and R. Okungbaye, "Stevioside modulates oxidative damage in the liver and kidney of high fat/low streptozocin diabetic rats", Heliyon., 4 (5), 1-20 (2018).

49- J. R. Lindsay, N. A. Duffy, A. M. McKillop, J. Ardill, F. P. M. O'Harte, P. R. Flatt, et al. "Inhibition of dipeptidyl peptidase IV activity by oral metformin in Type 2 diabetes", Diabetic Medicine, 22 (5), 654-7 (2005). 
50- B. Green, N. Irwin, A. Duffy N., V. Gault, F. O'Harte and P. Flatt, "Inhibition of dipeptidyl peptidase IV (DPPIV) activity by metformin enhances the anti-diabetic effects of glucagon-like peptide-1 (GLP1)", EJP, 192-9 (2006).

51- E. S. Ford, C. Li and N. Sattar, "Metabolic syndrome and incident diabetes: current state of the evidence", Diabetes Care, 31(9), 1898-904 (2008).

52- N. Sharma, R. Mogra and B. Upadhyay, "Effect of stevia extract intervention on lipid profile", Studies on EthnoMedicine, 3 (2), 137-40 (2009).

53- A. Aghajanyan, Z. Movsisyan and A. Trchounian, "Antihyperglycemic and Antihyperlipidemic Activity of Hydroponic Stevia rebaudiana Aqueous Extract in Hyperglycemia Induced by Immobilization Stress in Rabbits", BioMed. Research International, 2017, 16 (2017).

54- U. Ahmad, R. S. Ahmad, M. S. Arshad, Z. Mushtaq, S. M. Hussain and A. Hameed, "Antihyperlipidemic efficacy of aqueous extract of Stevia rebaudiana Bertoni in albino rats", Lipids in Health and Disease, 17 (1), 1-8 (2018).
55- T. Sudha, D. A. Devi and L. Kaviarasan, "Antihyperlipidemic effect of Stevia rebaudiana on Alloxan Induced Diabetic Rats", AJPT, 7 (4), 202-8 (2017).

56- D. Q. Luong, R. Oster and A. P. Ashraf, "Metformin treatment improves weight and dyslipidemia in children with metabolic syndrome", JPEM, 28 (5-6), 649-55 (2015).

57- S. H. Lin, P. C. Cheng, S. Te Tu, S. R. Hsu SR, Y. C. Cheng and Y. H. Liu, "Effect of metformin monotherapy on serum lipid profile in statin-naïve individuals with newly diagnosed type 2 diabetes mellitus: A cohort study", Peer J., 6, 1-10.

58- S. Zhang, H. Xu, X. Yu, Y. Wu and D. Sui, "Metformin ameliorates diabetic nephropathy in a rat model of low-dose streptozotocin-induced diabetes". Experimental and Therapeutic Medicine, 14 (1), 383-90 (2017). 


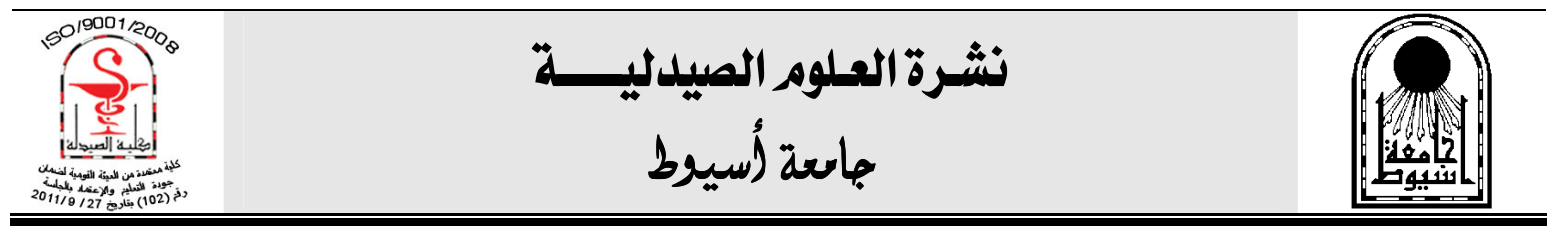

\section{ستيفيا تحسن تأثير الميتفورمين المضاد للسكرى فى الجرذان المصابة بالسكرى تم تمثئ

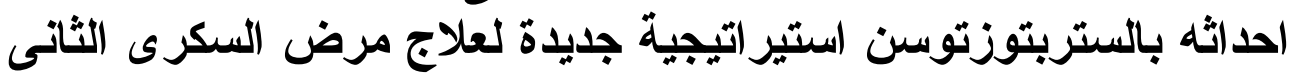

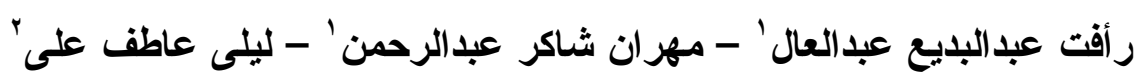

'قسم الفارماكولوجى ، كلية الطب ، جامعة اسيوط ، مصر

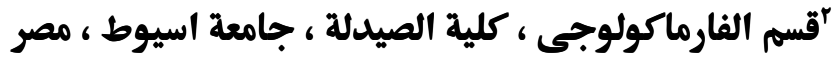

مرض السكري هو مشكلة صحية كبيرة تهدد العالم بأسره ووفقًا لتقارير منظمة الصحة العالمية

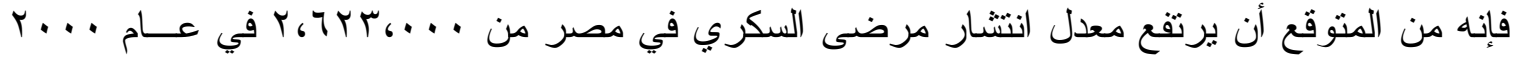

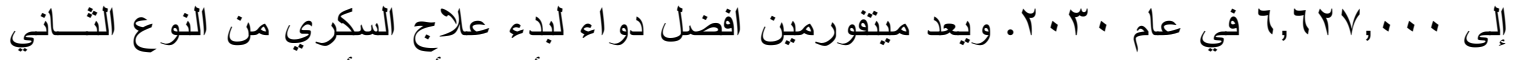

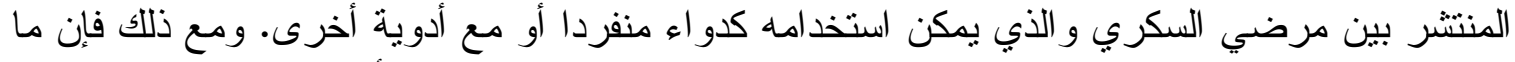

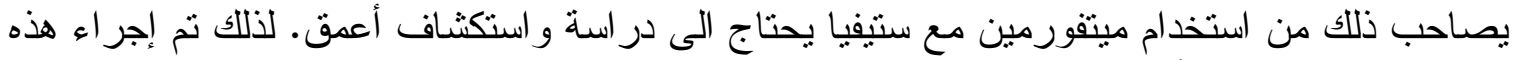

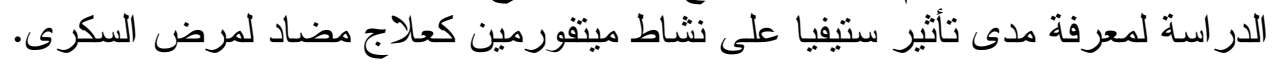

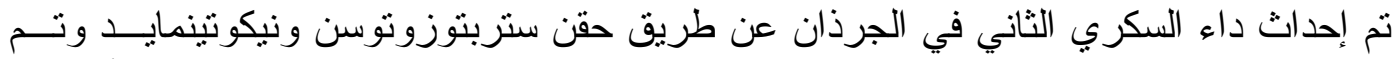

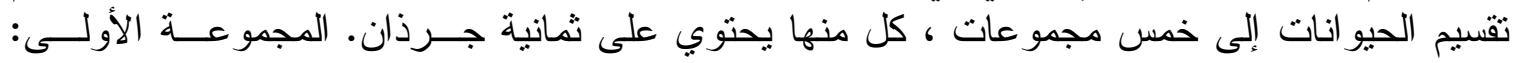

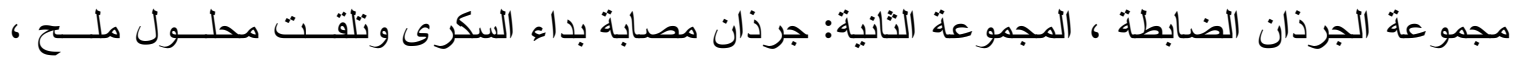

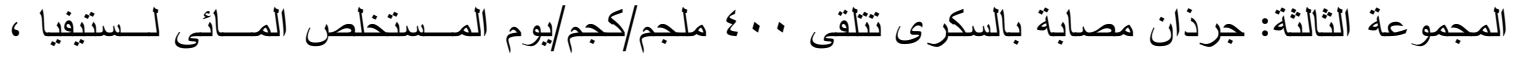

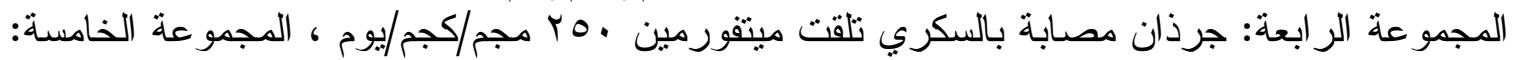

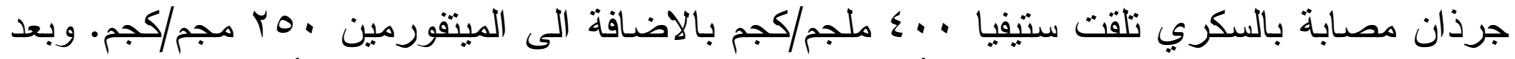

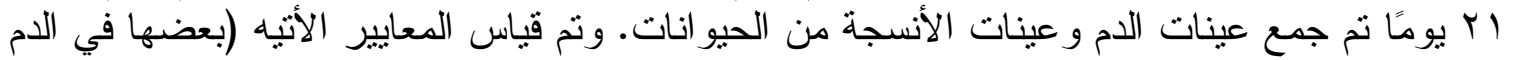

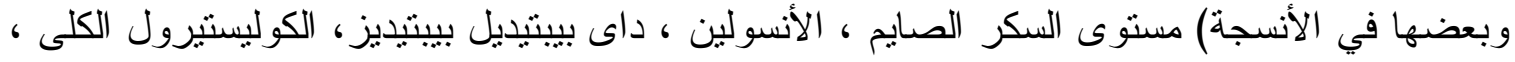

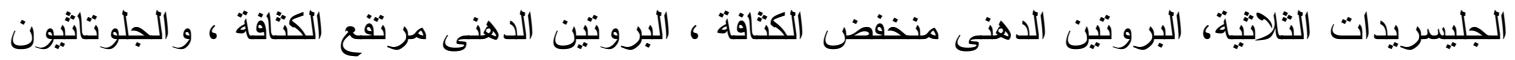

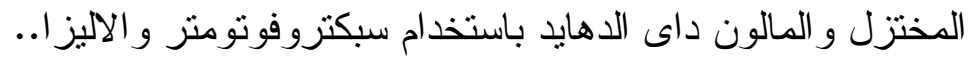

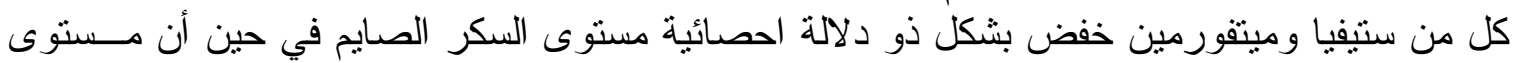

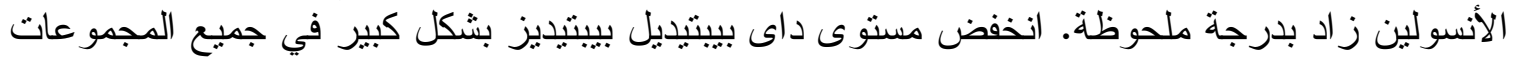

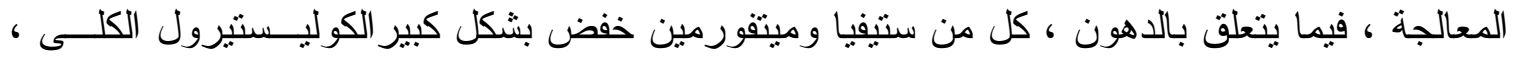

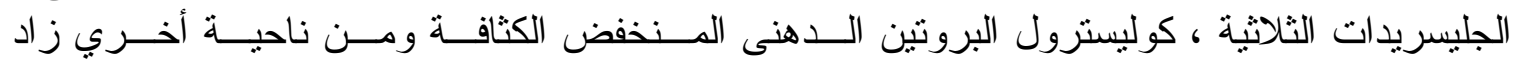

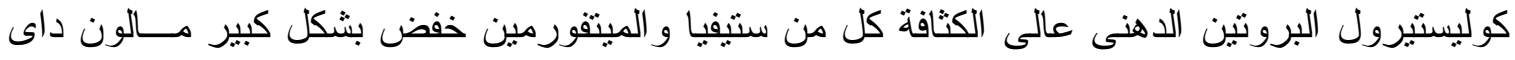

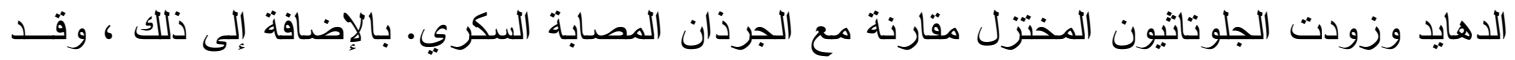

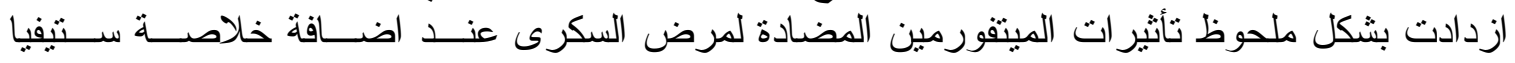

من هذه الدر اسة نستتتج ان: تمتلك ستيفيا تأثير مضاد للسكرى ويمكن أن تزيد من القدرة العلاجية

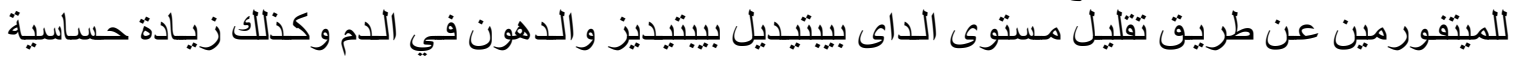
مستقبلات الأنسولين للانسولين وزيادة الجلوناثيون المختزل وتقليل المائيل المالون داى الدهايد. 